and RA pressure differences caused by the inadvertently misconnected IVC. This case stresses the role of intraoperative transesophageal echocardiographic analysis even in simple cases, such as an ASD.

\section{References}

1. Jacobs ML, Norwood WI. Fontan operation: influence of modifications on morbidity and mortality. Ann Thorac Surg. 1994;58:945-52.
2. Reed MK, Leonard SR, Zellers TM, Hisashi N. Major intrahepatic veno-venous fistulas after a modified Fontan operation. Ann Thorac Surg. 1996;61:713-5.

3. Schneider DJ, Banerjee A, Mendelson MM, Norwood WI. Hepatic venous malformation after modified Fontan procedure with partial hepatic vein exclusion. Ann Thorac Surg. 1997;63:1177-9.

4. Al Zaghal AM, Li J, Anderson RH, Lincoln C, Shore D, Rigby ML. Anatomical criteria for the diagnosis of sinus venosus defects. Heart. 1997;78:298-304.

5. Gaynor JW. Management of sinus venosus defects. Semin Thorac Cardiovasc Surg Pediatr Card Surg Annu. 2006;35-9.

6. Fouty BW, Lynch DA, Fontenot AP, Schwarz MI. Hypoxemia explained 36 years later. Chest. 2001;120:1739-40.

\title{
Optimism derived from 7.5 years of continuous-flow circulatory support
}

\author{
Stephen Westaby, PhD, ${ }^{\mathrm{a}}$ Adrian Banning, MD, ${ }^{\mathrm{a}}$ Desley Neil, MD, ${ }^{\mathrm{b}}$ Philip Poole-Wilson, F Med Sci, ${ }^{\mathrm{c}}$ and \\ O. Howard Frazier, MD, ${ }^{\mathrm{d}}$ Oxford, Birmingham, and London, United Kingdom; and Houston, Tex
}

Severely symptomatic heart failure is increasingly common as the population ages. Both prognosis and quality of life are poor. These patients have limited options. Few are eligible for cardiac transplantation because of age or the common transplant comorbidities of pulmonary hypertension and renal impairment. In New York Heart Association (NYHA) class IV patients, ventricular resynchronization therapy provides only marginal benefit that is insufficient to improve quality of life. ${ }^{1}$ Lifetime circulatory support has a firm evidence base in the REMATCH trial. ${ }^{2}$ Because of the complication rates in first-generation left ventricular assist devices (LVADs), the compelling argument for an off-the-shelf solution for advanced heart failure has been slow to progress.

In 2000, we reported the first implantation of a new miniaturized rotary blood pump with a novel power-delivery system designed for permanent use. ${ }^{3}$ At the time, there was skepticism about the ability of a nonpulsatile LVAD to sustain end-organ function on a long-term basis. In fact, the patient became the world's longest circulatory support survivor. We now describe the autopsy findings to conclude this experience.

\footnotetext{
From the Departments of Cardiac Surgery and Cardiology, ${ }^{a}$ John Radcliffe Hospital, Oxford, United Kingdom; the University Department of Pathology, ${ }^{\mathrm{b}}$ Selly Oak Hospital, Birmingham, United Kingdom; the Department of Cardiology, ${ }^{\mathrm{c}}$ Royal Brompton Hospital, London, United Kingdom; and the Department of Cardiac Surgery, ${ }^{\mathrm{d}}$ The Texas Heart Institute, Houston, Tex.

Disclosures: None.

Received for publication April 29, 2008; revisions received May 19, 2008; accepted for publication May 19, 2008; available ahead of print March 18, 2009.

Address for reprints: Stephen Westaby, PhD, Department of Cardiac Surgery, John Radcliffe Hospital, Headley Way, Headington, Oxford OX3 9DU, United Kingdom (E-mail: swestaby@AHF.org.uk).

J Thorac Cardiovasc Surg 2010;139:e45-7

0022-5223/\$36.00

Copyright (C) 2010 by The American Association for Thoracic Surgery

doi:10.1016/j.jtcvs.2008.05.072
}

\section{CLINICAL SUMMARY}

The patient was a 60 -year-old man with a 7-year history of symptomatic idiopathic dilated cardiomyopathy leading to breathlessness at rest, pitting edema to the thighs, ulcerated legs, and ascites, despite maximum medical therapy. Left ventricular ejection fraction was less than $10 \%$, with a cardiac index of $1.81 \mathrm{~L} \cdot \mathrm{min}^{-1} \cdot \mathrm{m}^{-2}$. Maximal oxygen consumption was $5.7 \mathrm{~mL} \cdot \mathrm{kg}^{-1} \cdot \min ^{-1}$ during exercise, and pulmonary vascular resistance was 7 Wood units. With a single functioning kidney and a creatinine clearance of $38 \mathrm{~mL} /$ min, he was not accepted for the transplant wait listing.

The Jarvik 2000 axial flow pump (Jarvik Heart, Inc, New York, NY) was implanted directly into the apex of the left ventricle with a Dacron graft to the descending thoracic aorta (Figure 1, A). The power-delivery system used a titanium pedestal screwed into the skull, providing a plug into which the external power line, battery, and controller were attached (Figure 1,B). ${ }^{4}$ Postoperative management included anticoagulation with warfarin to maintain an international normalized ratio of between 2.5 and 3.0, together with continuous pharmacologic afterload reduction. Mean blood pressure was between 80 and $90 \mathrm{~mm} \mathrm{Hg}$, usually with a pulse pressure of 10 to $15 \mathrm{~mm} \mathrm{Hg}$. At a pump rotor speed of 10,000 rpm, resting cardiac output was between 4.5 and $5.5 \mathrm{~L} /$ min. Over 3 months, the patient returned to NYHA class I.

He led a very active and productive life for 7.5 years. After the perioperative period, less than $5 \%$ of the follow-up duration was spent in the hospital. There were no pump malfunctions or thromboembolic complications. External cables and batteries were exchanged on numerous occasions through wear and tear. The skull pedestal remained infection free. Staphylococcal septicemia followed nasal cauterization for epistaxis but was successfully treated with a 3-month 

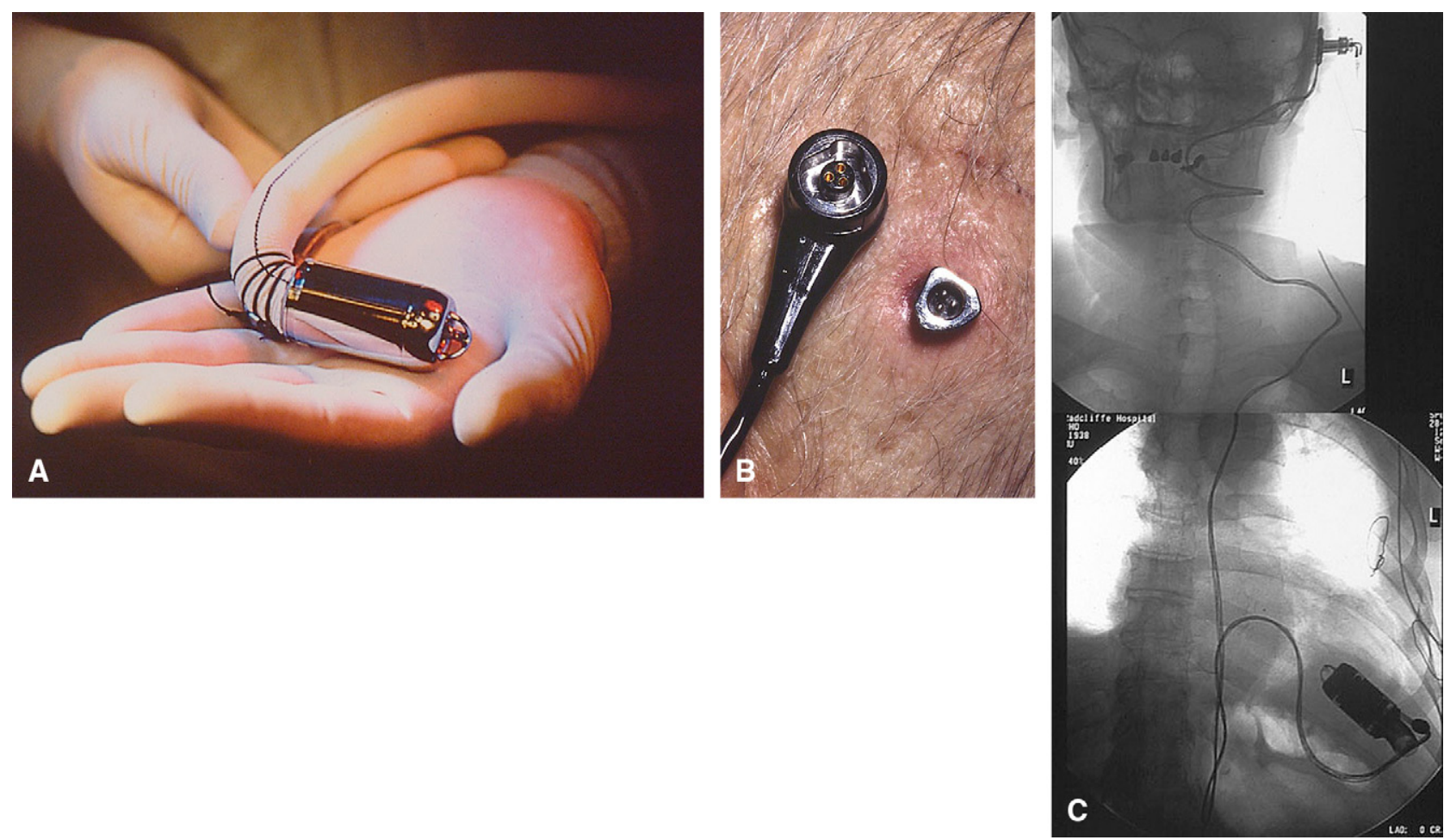

FIGURE 1. A, The Jarvik 2000 axial flow pump and vascular graft. B, The titanium skull pedestal designed to transmit electrical power across the skin while minimizing the risk of infection. Resistance to infection occurs through rigid fixation and highly vascular scalp skin without a subcutaneous fat layer. This was the first clinical application of the technique. C, Plain chest, neck, and skull radiographs showing the left ventricular assist device implanted within the left ventricle and the power cable passing through the pleural cavity and neck to the skull-fixed pedestal.

course of antibiotics. Over time, the performance of the LVAD remained unchanged, but heart and renal function deteriorated. In the last 2 years of life, he was in NYHA class II and troubled by rheumatoid arthritis and benign prostatic hypertrophy. The latter was managed by means of transurethral resection. He died at 68 years of age after profuse epistaxis and then acute renal failure. He was optimally anticoagulated with an international normalized ratio of 2.5 at the time. The overall cost per annum for this patient, including the LVAD, was $\$ 40,000$.

A detailed autopsy was performed, with removal of the intracardiac blood pump and power system intact. The left ventricle was hugely dilated (heart weight, $794 \mathrm{~g}$ ), but the coronary arteries were normal. Histology confirmed chronic idiopathic dilated cardiomyopathy, and the pulmonary arteries showed intimal thickening consistent with pulmonary hypertension. There was a thin crescent of densely adherent thrombus between the device and the septum of the left ventricle. No thrombus was found within the device or vascular graft. Careful examination of the brain, liver, kidneys, and gut provided no evidence for silent embolism, infarction, or hemorrhage. The kidneys showed globally sclerosed glomeruli and tubular atrophy, accounting for the chronic renal impairment. We were particularly interested in the long-term effects of attenuated pulse pressure, but apart from decreased numbers of smooth muscle cells in the aortic medial layer, no other changes in organ histology were detectable.
The axial flow pump itself showed only minimal wear in the ceramic bearings and continues to work normally during ongoing durability testing on the bench. The implanted power-delivery system was free from infection (Figure 1, $C)$. Consequently, there was no indication that any part of the mechanical system would fail in the foreseeable future.

\section{DISCUSSION}

This anecdotal experience illustrates the true potential for destination therapy and confirms that physiologic levels of pulse pressure are not a fundamental requirement in the human circulation. Modest increases in blood flow (range, 3-4 $\mathrm{L} / \mathrm{min}$ ) can relieve symptoms and reverse both the humeral and cytokine changes of heart failure. Although high-volume pulsatile LVAD flow might be preferable for moribund bridge-to-transplantation patients with multiple organ failure, the target population for destination therapy has chronic ambulatory heart failure and can be rendered asymptomatic with a continuous-flow device.

In our patient the LVAD sustained the systemic circulation and palliated symptoms for more than $10 \%$ of his overall lifespan. The cost did not exceed the benchmark $\$ 50,000$ per added life-year for patients undergoing renal dialysis. A second patient receiving a Jarvik 2000 is approaching 7 years of survival (F. Beyersdorf, personal communication), whereas the Berlin INCOR (Berlin Heart, Berlin, Germany) and HeartMate 
II (Thoratec, Pleasanton, Calif) axial flow pumps have sustained patients for 4 years. Given the reservations about survival advantage and economic viability of cardiac transplantation in United Network for Organ Sharing status II patients, properly structured clinical trials to compare LVADs with transplantation or continued medical therapy are indicated and probably overdue. ${ }^{5}$ Indeed, for those who wish to avoid the side effects of immunosuppression, a rotary blood pump might provide a realistic alternative to a donor heart.

In the meantime, rotary blood pumps can offer symptomatic relief for many patients with heart failure who will never reach a transplant waiting list.

\section{References}

1. McAlister FA, Ezekowitz J, Hooton N, et al. Cardiac resynchronisation therapy for patients with left ventricular systolic dysfunction. A systematic review. JAMA. 2007;297:2502-14

2. Rose E, Gelijns A, Moskowitz A, et al. Long term mechanical left ventricular assistance for end stage heart failure. N Engl J Med. 2001;345:1435-43.

3. Westaby S, Banning AP, Jarvik RK, et al. First permanent implant of the Jarvik 2000 heart. Lancet. 2000;356:900-3.

4. Westaby S, Jarvik RK, Freeland A, et al. Post auricular power delivery for permanent mechanical circulatory support. J Thorac Cardiovasc Surg. 2002; 123:977-83.

5. Cadeiras M, Von Beyern MP, Deng M. Cardiac transplantation. Any role left? Heart Fail Clin. 2007;3:321-48.

\title{
Successful lung transplantation in an octogenarian
}

\author{
Norihisa Shigemura, MD, Stacey Brann, MD, Susan Wasson, CRNP, Jay Bhama, MD, \\ Christian Bermudez, MD, Brack G. Hattler, MD, Bruce Johnson, MD, Maria Crespo, MD, \\ Joseph Pilewski, MD, and Yoshiya Toyoda, MD, Pittsburgh, Pa
}

Advanced recipient age continues to be used as an exclusion criterion for lung transplantation. ${ }^{1}$ However, given the changing age demographics in most developed countries, redefinition of the appropriate recipient age limit for lung transplantation is needed because it has become an established therapeutic option with acceptable mortality for endstage lung diseases. Given those conditions, we recently have expanded our criteria for both recipients and donors in lung transplantation. ${ }^{2}$ We present the case of an 81-year-old man with idiopathic pulmonary fibrosis (IPF) who is the oldest known successful lung transplant recipient reported.

\section{CLINICAL SUMMARY}

An 81-year-old man who had been an active businessman and enjoyed golf after retirement was given a diagnosis of IPF in 2005 and treated with oral steroids and azathioprine. $\mathrm{He}$ became oxygen dependent and severely limited in activities of daily living (from Fletcher Hugh-Jones criteria 4 to 5). After failing all other therapeutic initiatives, he was referred to one major medical center in the United States for lung transplantation evaluation. However, because of his advanced

\footnotetext{
From Cardiopulmonary Transplantation, University of Pittsburgh Medical Center, Pittsburgh, $\mathrm{Pa}$.

Disclosures: None.

Received for publication Jan 21, 2008; revisions received May 26, 2008; accepted for publication June 22, 2008; available ahead of print March 12, 2009.

Address for reprints: Norihisa Shigemura, MD, Department of Thoracic Surgery, Osaka University Graduate School of Medicine, L5, 2-2 Yamada-oka, Suita, Osaka, 565-0871 Japan (E-mail: shigemura@thoracic.med.osaka-u.ac.jp).

J Thorac Cardiovasc Surg 2010;139:e47-8

$0022-5223 / \$ 36.00$

Copyright (c) 2010 by The American Association for Thoracic Surgery doi:10.1016/j.jtcvs.2008.06.044
}

age, he was declined and referred to our center to re-evaluate his lung transplantation candidacy. Although the patient had a past history of prostate cancer in 1992, there was no evidence of recurrence during the 5 years before our re-evaluation, and he was deemed a suitable candidate based on our multidisciplinary transplant selection committee criteria. At the time of listing, he had severely restrictive pulmonary function, with a forced vital capacity of $1.59 \mathrm{~L}(41 \%$ of predicted value), a forced expiratory volume in 1 second of 1.35 $\mathrm{L}$ ( $56 \%$ of predicted value), and a diffusion capacity for carbon monoxide of $3.88 \mathrm{~L} / \mathrm{min} / \mathrm{kpa}$ ( $23 \%$ of predicted value). Furthermore, blood gas on room air showed a $\mathrm{Po}_{2}$ of $48 \mathrm{~mm}$ $\mathrm{Hg}$ and a $\mathrm{PCO}_{2}$ of $36 \mathrm{~mm} \mathrm{Hg}$. The 6-minute walk results were 770 feet on $6 \mathrm{~L}$ of oxygen through a nasal cannula with desaturation to $85 \%$. Cardiac catheterization showed a systolic pulmonary artery pressure of $43 \mathrm{~mm} \mathrm{Hg}$, a transpulmonary gradient of $15 \mathrm{~mm} \mathrm{Hg}$, and mild coronary artery disease. A chest radiograph on admission is shown in Figure 1, $A$.

In April 2007, a 51-year-old man with no smoking history became available as a donor. The donor was 66 inches in height, whereas the recipient was 68 inches. We performed a left single-lung transplantation without cardiopulmonary bypass, during which the allograft ischemic time was 245 minutes. Immunosuppressive therapy consisted of intravenous alemtuzumab (Campath-1H; Genzyme Corporation, Cambridge, Mass) as induction therapy, with oral tacrolimus, mycophenolate mofetil, and prednisone administered postoperatively. Recovery from the procedure was uneventful. $\mathrm{He}$ was extubated on postoperative day 1 and was discharged from the hospital 21 days after transplantation without supplemental oxygen. At present, 1 year after transplantation, the 